\title{
Hearing Threshold Evaluation in Children Using Narrow Band Chirp Auditory Brainstem Response and Tone Burst Auditory Brainstem Response
}

\author{
Hossam Sanyelbhaa Talaat ${ }^{1}$, Alshymaa Hammad ${ }^{2}$, Ahmed Mahmoud Zein El Abedein ${ }^{3}$ \\ ${ }^{1}$ Audiology Unit, Faculty of Medicine, Menoufia University, Al Minufya, Egypt \\ ${ }^{2}$ Shibin El-Kom Teaching Hospital, Shibin El-Kom, Egypt \\ ${ }^{3}$ Faculty of Medicine, Menoufia University, Al Minufya, Egypt \\ Email:am_zein14@yahoo.com
}

How to cite this paper: Talaat, H.S., Hammad, A. and El Abedein, A.M.Z. (2020) Hearing Threshold Evaluation in Children Using Narrow Band Chirp Auditory Brainstem Response and Tone Burst Auditory Brainstem Response. International Journal of Otolaryngology and Head \& Neck Surgery, 9, 30-37.

https://doi.org/10.4236/ijohns.2020.91005

Received: August 8, 2019

Accepted: December 30, 2019

Published: January 2, 2020

Copyright $\odot 2020$ by author(s) and Scientific Research Publishing Inc. This work is licensed under the Creative Commons Attribution International License (CC BY 4.0).

http://creativecommons.org/licenses/by/4.0/

(c) (i) Open Access

\begin{abstract}
Objectives: Correlation between Narrow Band Chirp Auditory Brainstem Response (NB-CE chirp ABR) as a frequency specific method for hearing threshold detection in children and Tone burst Auditory Brainstem Response (Tb-ABR) in reference to behavioral hearing threshold audiometry. Material and Methods: This study was conducted on 100 patients at audiology unit, Menoufia University hospital, in the period from Oct. 2015 to Feb. 2017. Patients enrolled within this study were classified into four groups: Group I: included 40 patients diagnosed with normal hearing, Group II: included 48 patients with mild to moderate sensorineural hearing loss (SNHL), Group III: included 56 patients with moderate to moderately severe SNHL and Group IV: included 56 patients with severe to profound SNHL. All patients' enrolled NB-CE chirp ABR, Tb-ABR as well as pure tone audiogram (PTA). Results: there was a significant correlation between NB-CE chirp ABR and PTA hearing threshold. The use of a chirp-ABR testing ensures higher sensitivity and accuracy than that of $\mathrm{Tb}-\mathrm{ABR}$ for measuring frequency-specific thresholds in young children. Conclusion: NB-CE Chirp ABR is more efficient than $\mathrm{Tb}-\mathrm{ABR}$ as a frequency specific tool for hearing threshold estimation in children.
\end{abstract}

\section{Keywords}

Chirp-ABR, Tb-ABR, PTA, SNHL 


\section{Introduction}

Hearing assessment of children is a major audiological concern, so as to early detect and manage hearing impairment, thus avoiding delayed speech development and its social, emotional, cognitive and academic hazards [1]. Substantial progress has been made in the technology used and in the implementation of newborn hearing screening (NHS) programs worldwide [2]. Evoked-potential audiometry (evoked with either click or tone burst stimuli) is used to measure hearing thresholds in young children and other individuals who cannot complete behavioral audiometric tests. Click Auditory Brainstem Response (ABR) thresholds correlate with behavioral thresholds at $(2-4) \mathrm{kHz}$ range (but cannot be used to reliably estimate low-frequency hearing thresholds) [3]. The tone burst $\mathrm{ABR}$ (Tb-ABR), therefore, is used to evaluate frequency specific hearing threshold. More recently, Narrow Band Chirp Auditory Brainstem Response (NB-CE chirp ABR) has been available for providing hearing threshold information as a function of frequency. The chirp concept was first used in auditory electrophysiology by Shore and Nuttal [4]. It has been studied intensively to be used in the auditory field by Elberling et al. [5]. The CE-Chirp is a family of stimuli designed to compensate for the cochlear travel delay and provide enhanced neural synchronicity [6]. This was done through equations based on Brainstem Auditory Evoked Potentials (BAEP) latencies recorded in humans [7]. The broadband CE-Chirp is decomposed into four filtered narrow band chirps (NB CE-Chirp) with center frequencies 500, 1000, 2000 and $4000 \mathrm{~Hz}$ [4]. This study was performed to correlate between (NB-CE chirp ABR) as a frequency specific method for hearing threshold detection in children and (Tb-ABR) in reference to behavioural hearing threshold audiometry.

\section{Material and Methods}

The study was carried out at audiology unit, Menoufia University hospital, from Oct. 2015 to Feb. 2017 after obtaining ethics committee approval in 2015 and informed written consent from all subjects. One hundred subjects aged $8-12$ years of both sex with normal middle ear function were included in the study. Subjects were classified into four groups according to behavioral methods (play-conventional audiometry) as group I includes 40 subjects diagnosed as normal hearing sensitivity. Group II: included 48 subjects diagnosed as mild to moderate SNHL. Group III included 56 subjects diagnosed as moderate to moderately severe SNHL. Group IV: included 56 subjects diagnosed as severe to profound SNHL. Exclusion criteria include any neurological, mental abnormality or any other ENT problem.

All subjects in the four groups underwent pure tone audiometry using Madsen Orbiter 922 in a sound treated room amplisilence and ABR testing using (NB-CE chirp and tone burst) stimuli using interacoustic, Eclipse 25 for hearing threshold evaluation. Both narrow band Chirp stimuli and tone bursts stimuli at frequencies 500,1000, 2000 and $4000 \mathrm{~Hz}$ were used with intensity $90 \mathrm{dBnHL}$ 
down to the threshold with alternating polarity at a repetition rate 19.1 for both NB-CE-Chirp stimuli and TB stimuli. The stimuli were presented to each ear via ER3A insert phone.

\subsection{Statistical Analysis}

Statistical analysis was performed using SPSS version 20. One sample t-test, chi-square test and ANOVA test with post Hoc test for detection of the statistical significance between different parameters of the ABR results. P-value was considered significant when $\leq 0.05$.

\subsection{Results}

The age of patients ranged from 8 to 12 years. There were no statistically significant differences among the groups as regards age or sex (Table 1). Results of the study will be presented as follows; detectability of wave $\mathrm{V}$ till hearing threshold and comparison of wave $\mathrm{V}$ latency and amplitude between TB-ABR and NB-Chirp stimuli of all tested groups (Table 2 and Table 3) (Figures 1-4).

\section{Discussion}

\section{1) As regard threshold differences:}

In NB CE-chirp ABR and Tb-ABR hearing thresholds were significantly overestimating behavioral thresholds. The differences were higher at $500 \mathrm{~Hz}$ and lower at $4000 \mathrm{~Hz}$. In NB CE-chirp ABR, the difference at $500 \mathrm{~Hz}$ was $23.72 \mathrm{~dB}$ and $5.64 \mathrm{~dB}$ at $4000 \mathrm{~Hz}$. In Tb-ABR, hearing thresholds differ by about $18.2 \mathrm{~dB}$ at 500 and $2.7 \mathrm{~dB}$ at $4000 \mathrm{~Hz}$. These differences in the hearing threshold decreased with increased degree of hearing loss (Table 3) (Figures 1-4). These results agree with Federico et al. [8] and Almeida et al. [9]. This may be explained by the difference in temporal integration between normal listeners and those with hearing loss. Temporal integration refers to the dependence of behavioral threshold on stimulus duration, as short-duration sounds require higher levels for detection, compared to sounds of longer duration [10]. There were significant differences of hearing threshold levels between chirp ABR and Tb ABR at 500, $4000 \mathrm{~Hz}$. No significance was shown at 1000, $2000 \mathrm{~Hz}$ in all groups. Rodrigues et al. have compared ABR responses evoked by NB-CE chirp and tone burst in normal hearing infants. They stated that data from hearing impaired infants can

Table 1. Age and gender distribution.

\begin{tabular}{|c|c|c|c|c|c|c|c|c|c|}
\hline & \multicolumn{2}{|c|}{$\begin{array}{c}\text { Group } 1 \\
(n=40) \\
\text { Mean } \pm \text { SD }\end{array}$} & \multicolumn{2}{|c|}{$\begin{array}{c}\text { Group } 2 \\
(n=48) \\
\text { Mean } \pm \text { SD }\end{array}$} & \multicolumn{2}{|c|}{$\begin{array}{c}\text { Group } 3 \\
(\mathrm{n}=56) \\
\text { Mean } \pm \text { SD }\end{array}$} & \multicolumn{2}{|c|}{$\begin{array}{c}\text { Group } 4 \\
(n=56) \\
\text { Mean } \pm \text { SD }\end{array}$} & P-value \\
\hline \multirow[t]{2}{*}{ Age } & \multicolumn{2}{|c|}{$8.32 \pm 1.74$} & \multicolumn{2}{|c|}{$9.27 \pm 1.52$} & \multicolumn{2}{|c|}{$9.1 \pm 2.08$} & \multicolumn{2}{|c|}{$8.82 \pm 1.72$} & 0.059 \\
\hline & No. & $\%$ & No. & $\%$ & No. & $\%$ & No. & $\%$ & \\
\hline \multicolumn{10}{|l|}{ Gender: } \\
\hline Male & 16 & 40.0 & 28 & 58.3 & 36 & 64.3 & 32 & 57.1 & 0.11 \\
\hline Female & 24 & 60.0 & 20 & 41.7 & 20 & 35.7 & 24 & 42.9 & \\
\hline
\end{tabular}


Table 2. Amplitude and latency correlation between chirp ABR and Tb ABR.

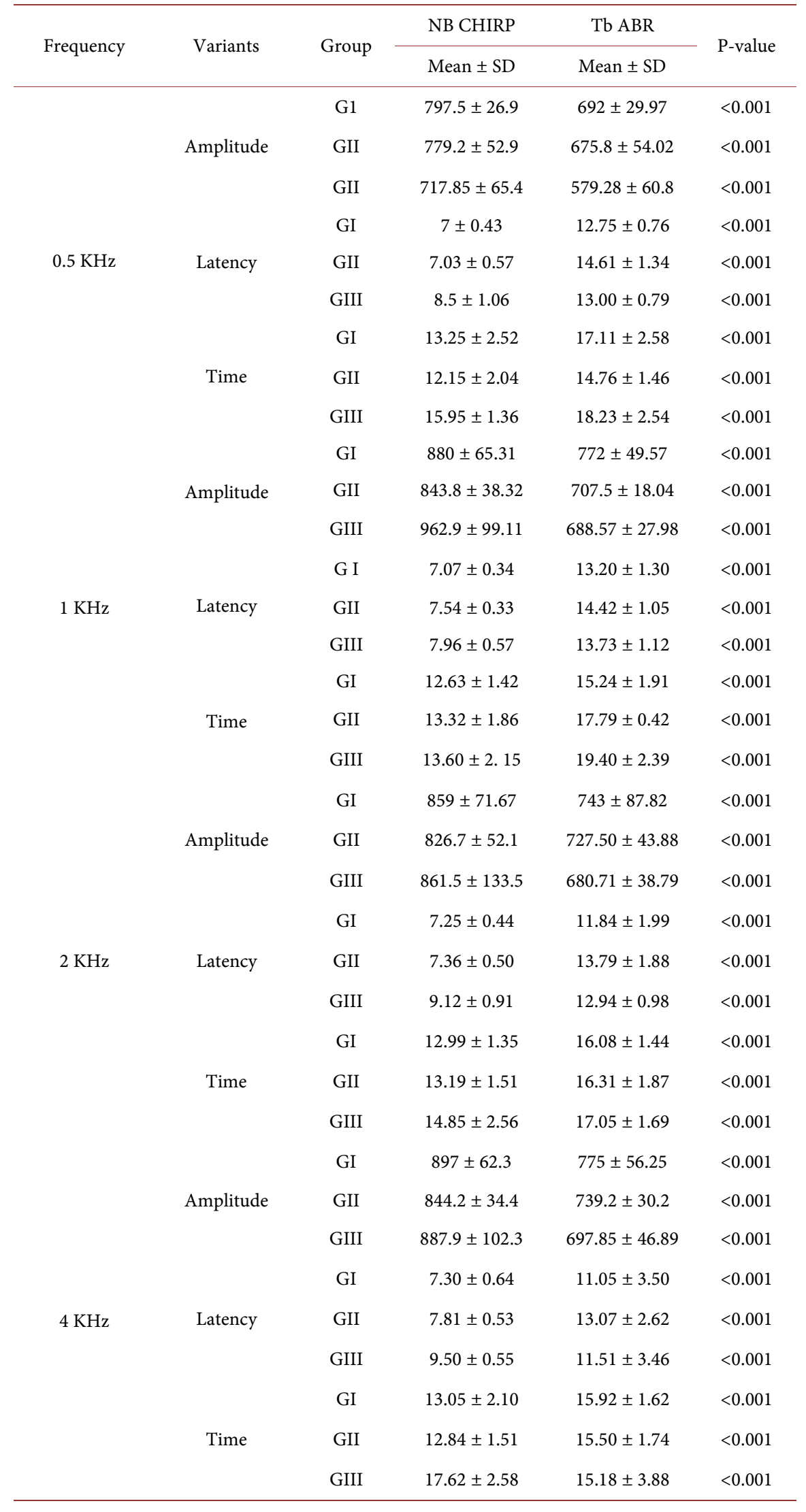


Table 3. Post HOC test between PTA, chirp ABR, Tb-ABR among 4 groups.

\begin{tabular}{ccccc}
\hline & & $\mathrm{P} 1$ & $\mathrm{P} 2$ & $\mathrm{P} 3$ \\
\hline \multirow{3}{*}{ GI } & 500 & $\mathrm{P} 1<0.001$ & $\mathrm{P} 1<0.001$ & $\mathrm{P} 3<0.001$ \\
& 1000 & $\mathrm{P} 1<0.001$ & $\mathrm{P} 2<0.001$ & $\mathrm{P} 3=0.43$ \\
& 2000 & $\mathrm{P} 1<0.001$ & $\mathrm{P} 2<0.001$ & $\mathrm{P} 3=1.00$ \\
& 4000 & $\mathrm{P} 1=0.25$ & $\mathrm{P} 2<0.001$ & $\mathrm{P} 3=0.24$ \\
& 500 & $\mathrm{P} 1<0.001$ & $\mathrm{P} 2<0.001$ & $\mathrm{P} 3<0.001$ \\
GII & 1000 & $\mathrm{P} 1<0.001$ & $\mathrm{P} 2<0.001$ & $\mathrm{P} 3=0.04$ \\
& 2000 & $\mathrm{P} 1<0.001$ & $\mathrm{P} 2<0.001$ & $\mathrm{P} 3=0.01$ \\
& 4000 & $\mathrm{P} 1<0.001$ & $\mathrm{P} 2=0.86$ & $\mathrm{P} 3<0.001$ \\
& 500 & $\mathrm{P} 1<0.001$ & $\mathrm{P} 2<0.001$ & $\mathrm{P} 3=0.02$ \\
& 1000 & $\mathrm{P} 1<0.001$ & $\mathrm{P} 2<0.001$ & $\mathrm{P} 3=0.18$ \\
& 2000 & $\mathrm{P} 1<0.001$ & $\mathrm{P} 2<0.001$ & $\mathrm{P} 3=0.09$ \\
& 4000 & $\mathrm{P} 1<0.001$ & $\mathrm{P} 2=0.02$ & $\mathrm{P} 3<0.001$ \\
& 500 & $\mathrm{P} 1<0.001$ & $\mathrm{P} 2<0.001$ & $\mathrm{P} 3=0.68$ \\
& 1000 & $\mathrm{P} 1=0.12$ & $\mathrm{P} 2<0.001$ & $\mathrm{P} 3=0.18$ \\
& & & No 3 significant differences & \\
& 2000 & $\mathrm{P} 1=0.11$ & $\mathrm{P} 2=0.01$ & $\mathrm{P} 3=0.78$ \\
\hline
\end{tabular}

(p1): Comparison between PTA and CHIRP ABR. (p2): Comparison between PTA and TB ABR. (p3): Comparison between CHIRP ABR and TB ABR.

contribute to better understanding of narrow band CE-chirp stimuli in the cochlea [11].

2) As regards amplitude and latency difference between $T b A B R$ and chirp $A B R$ :

The ABR wave responses in NB chirp ABR showed statistically higher amplitudes than $\mathrm{Tb} A B R$ in all frequencies $(0.5,1,2$ and $4 \mathrm{kHz}$ ) (Table 2). This agreed with Don et al. [12] and Mùhler et al. [13] who found that the chirp-stimulus evoked ABR showed significantly larger amplitudes than that of click-ABR. The $A B R$ wave latencies were significantly shorter in CE-Chirp octave bands ABR than tone bursts $A B R$ at all four frequencies. This agreed with Musiek et al. [14] who demonstrated wave V latencies to $60 \mathrm{~dB}$ nHL CE-Chirp octave band stimuli in normal-hearing young adults. These latency differences have been attributed to the input compensation technique applied to chirp stimuli in some AEP software.

\section{3) As regards time needed to complete each test.}

NB chirp ABR has less test time than Tb ABR. Also, behavioral PTA has smaller time than Chirp ABR and Tb ABR (Table 2). This agreed with Dau et al. [15]. As chirp stimuli have short test time by aligning the arrival time of each frequency component in the stimulus to its place of maximum excitation along the basilar membrane. Such compensation will make the stimulus more efficient by achieving higher temporal synchronization between the evoked activities from the different neural elements that contribute to the formation of not only 


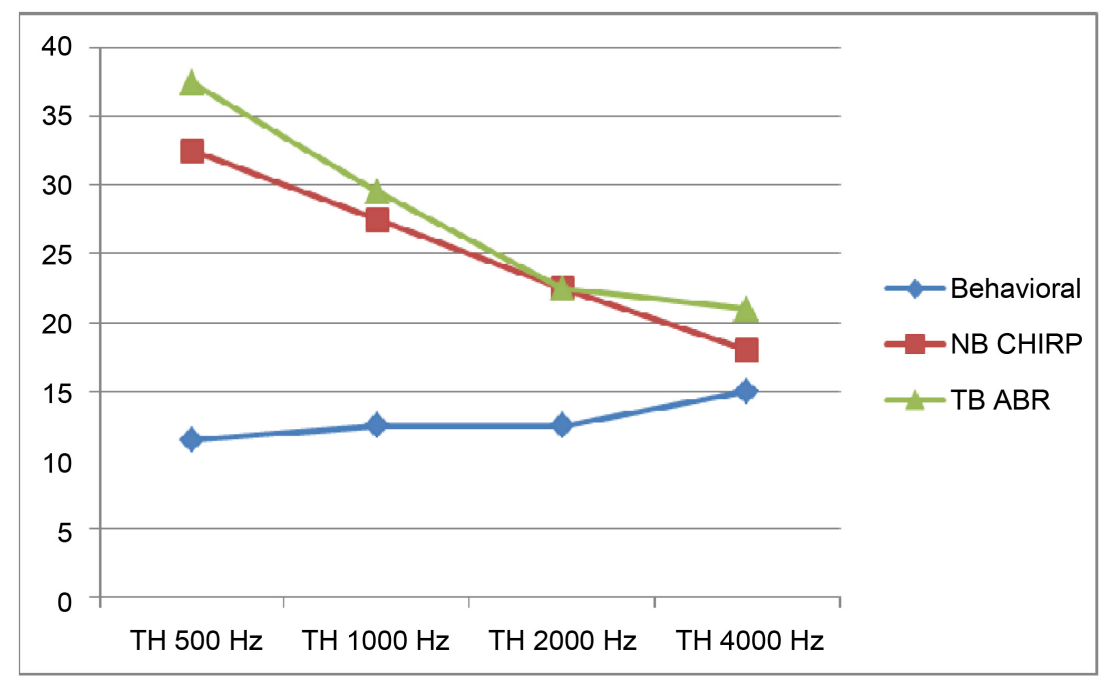

Figure 1. Threshold difference between chirp ABR and Tb-ABR and PTA in GI.

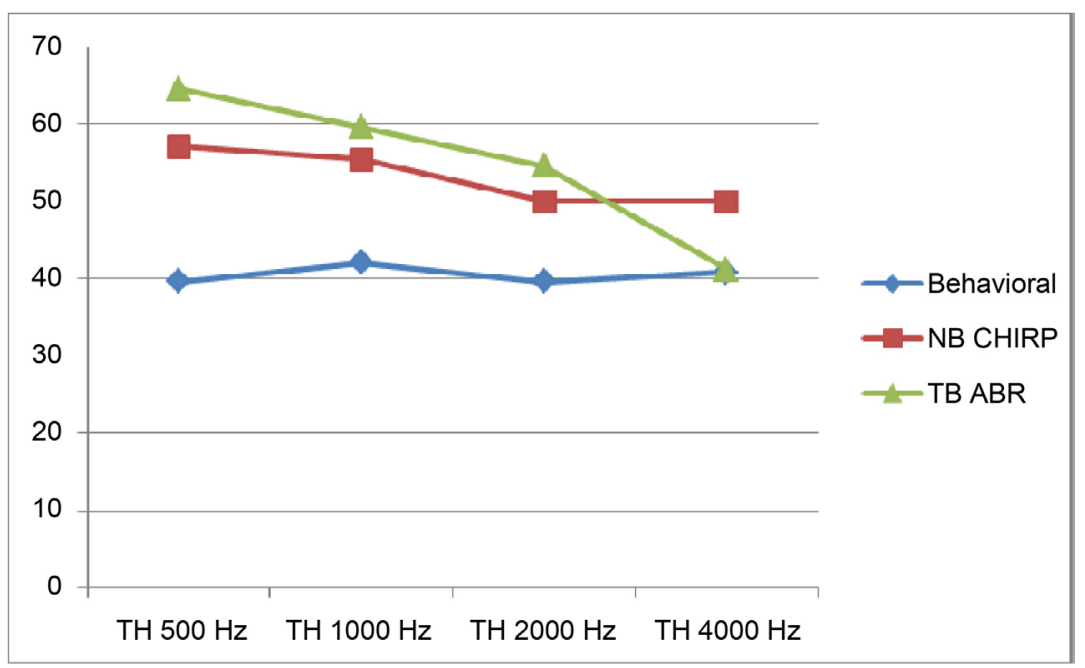

Figure 2. Threshold difference between chirp ABR and Tb-ABR and PTA in GII.

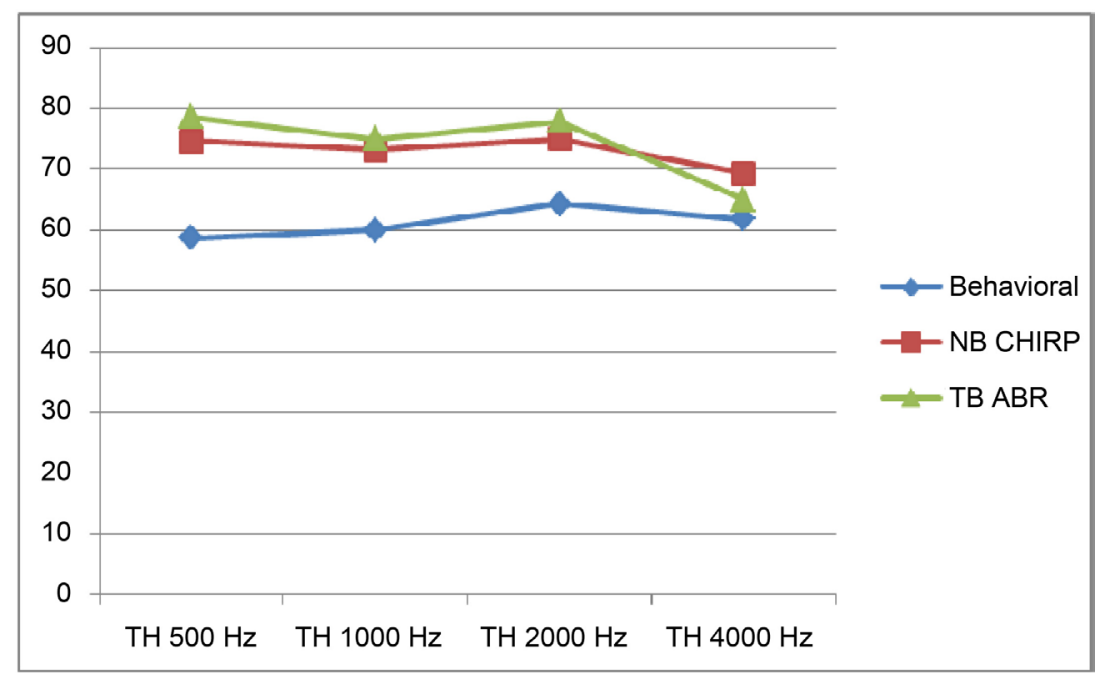

Figure 3. Threshold difference between chirp ABR and Tb-ABR and PTA in GIII. 


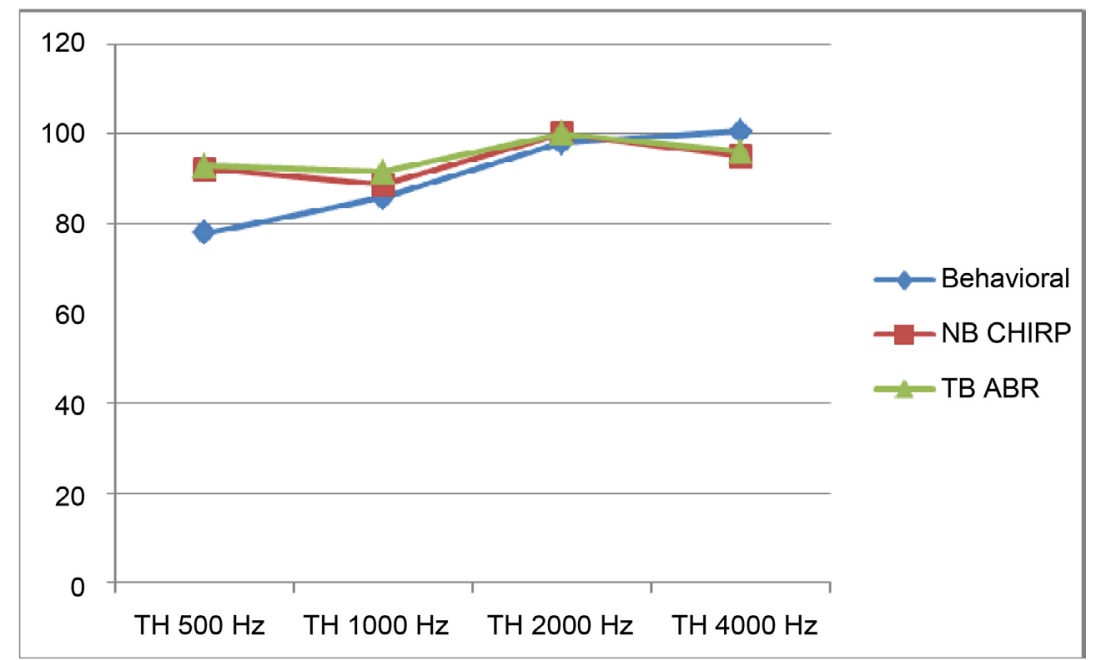

Figure 4. Threshold difference between chirp ABR and Tb-ABR and PTA in GIV.

ACAP but also the ABR and ASSR.

\section{Conclusion}

The use of a chirp-ABR testing ensures higher sensitivity and accuracy than that of $\mathrm{Tb}-\mathrm{ABR}$ for measuring frequency-specific thresholds in young children. Chirp ABR consumes less time than tone burst ABR. CE-chirp ABR has larger responses than $\mathrm{Tb}-\mathrm{ABR}$ responses in normal and hearing impaired children at all presentation levels. Regarding pure tone threshold prediction values of Tb-ABR stimuli, the best prediction was at $4000 \mathrm{~Hz}$ in normal hearing and hearing impaired children respectively, while the poorest prediction was at 500 $\mathrm{Hz}$ in all groups.

\section{Acknowledgements}

The authors like to thank members of audiology unit, Menoufia university hospitals for research support.

\section{Conflicts of Interest}

The authors declare no financial or other conflicts of interest related to this work.

\section{Ethical Approval}

All procedures performed in the study were in accordance with the ethical standards of the institutional research committee.

\section{References}

[1] Picton, W., Dimitrijevic, A., Perez, M. and Von Roon, P. (2005) Estimating Audiometric Thresholds Using Auditory Steady State Responses. Journal of the American Academy of Audiology, 16, 140-156. https://doi.org/10.3766/jaaa.16.3.3

[2] Sininger, Y., Hunter, L., Hayes, D., Roush, P. and Uhler, K. (2018) Evaluation of Speed and Accuracy of Next-Generation Auditory Steady State Response and Au- 
ditory Brainstem Response Audiometry in Children with Normal Hearing and Hearing Loss. Ear and Hearing, 39, 1207-1223.

https://doi.org/10.1097/AUD.0000000000000580

[3] Stapells, D.R., Gravel, J.S. and Martin, B.A. (1995) Thresholds for Auditory Brain Stem Responses to Tones in Notched Noise from Infants and Young Children with Normal Hearing or Sensorineural Hearing Loss. Ear and Hearing, 16, 361-371. https://doi.org/10.1097/00003446-199508000-00003

[4] Shore, S.E. and Nuttal, A.L. (1985) High-Synchrony Cochlear Compound Action Evoked Byrising Frequency-Swept Tone Bursts. The Journal of the Acoustical Society of America, 78, 1283-1295. https://doi.org/10.1121/1.392898

[5] Elberling, C., Don, M., Cebulla, M. and Sturzebecher, E. (2007) Auditory Steady-State Responses to Chirp Stimuli Based on Cochlear Traveling Wave Delay. The Journal of the Acoustical Society of America, 122, 2772-2785.

https://doi.org/10.1121/1.2783985

[6] Elberling, C. and Don, M. (2008) Auditory Brainstem Responses to a Chirp Stimulus Designed from Derived-Band Latencies in Normal-Hearing Subjects. The Journal of the Acoustical Society of America, 124, 3022-3037.

https://doi.org/10.1121/1.2990709

[7] Sturzebecher, E., Cebulla, M., Elberling, C. and Berger, T. (2006) New Efficient Stimuli for Evoking Frequency-Specific Auditory Steady-State Responses. Journal of the American Academy of Audiology, 17, 448-461. https://doi.org/10.3766/jaaa.17.6.6

[8] Federico, D., Andrea, C., Michelangelo, L. and Roberto, A. (2014) Tone Burst Stimulus for Auditory Brainstem Responses: Prediction of Hearing Threshold at 1 kHz. Auris Nasus Larynx, 41, 27-30. https://doi.org/10.1016/j.anl.2013.07.004

[9] Almeida, M., Rodrigues, G. and Doris, D. (2011) Frequency-Specific Auditory Brainstem Response in Infants with Normal Hearing. Revista CEFAC, 13, 489-495. https://doi.org/10.1590/S1516-18462010005000064

[10] Rance, G., Coone-Wesson, B., Wunderlich, J. and Dowell, R. (2002) Speech Perception and Cortical Event-Related Potentials in Children with Auditory Neuropathy. Ear and Hearing, 23, 239-253. https://doi.org/10.1097/00003446-200206000-00008

[11] Rodrigues, G., Ramos, N. and Lewis, D. (2013) Comparing Auditory Brainstem Responses (ABRs) to Toneburst and Narrow Band CE-Chirp in Young Infants. International Journal of Pediatric Otorhinolaryngology, 77, 1555-1560. https://doi.org/10.1016/j.ijporl.2013.07.003

[12] Don, M., Elberling, C. and Malof, E. (2011) Input and Output Compensation for the Cochlear Traveling Wave Delay in Wide-Band ABR Recordings: Implications for Small Acoustic Tumor Detection. Journal of the American Academy of Audiology, 20, 99-108. https://doi.org/10.3766/jaaa.20.2.3

[13] Mühler, R., Rahne, T. and Verhey, J. (2013) Auditory Brainstem Responses to Broad-Band Chirps: Amplitude Growth Functions in Sedated and Anaesthetized Infants. International Journal of Pediatric Otorhinolaryngology, 77, 49-53. https://doi.org/10.1016/j.ijporl.2012.09.028

[14] Musiek (2015) Auditory Brainstem Response Differential Diagnosis. In: Katz, J., Ed., Handbook of Clinical Audiology, Lippincott Williams \& Wilkins, Philadelphia, Ch. 13, 231-248.

[15] Dau, T., Wagner, O., Mellert, V. and Kollmeier, B. (2000) Auditory Brainstem Responses with Optimized Chirp Signals Compensating Basilar Membrane Dispersion. The Journal of the Acoustical Society of America, 107, 1530-1540. https://doi.org/10.1121/1.428438 